Int. J. Dev. Biol. 55: 861-867

doi: $10.1387 /$ ijdb.113371dl

\title{
Tumor-associated macrophages in breast cancer: distinct subsets, distinct functions
}

\author{
DAMYA LAOUI, KIAVASH MOVAHEDI, EVA VAN OVERMEIRE, JAN VAN DEN BOSSCHE, \\ ELIO SCHOUPPE, CAMILLE MOMMER, ALEXANDROS NIKOLAOU, YANNICK MORIAS, \\ PATRICK DE BAETSELIER and JO A. VAN GINDERACHTER*
}

\author{
Lab of Cellular and Molecular Immunology and Lab of Cellular and Molecular Immunology, \\ Department of Molecular and Cellular Interactions, Vrije Universiteit Brussel, Brussels, Belgium
}

\begin{abstract}
Macrophages display remarkable plasticity, allowing these cells to adapt to changing microenvironments and perform functions as diverse as tissue development and homeostasis, inflammation, pathogen clearance and wound healing. Macrophage activation can be triggered by Th1 cytokines and pathogen-associated or endogenous danger signals, leading to the formation of classically activated or M1 macrophages. On the other hand, anti-inflammatory mediators, including IL-4, IL-10, TGF- $\beta$ and M-CSF, induce diverse anti-inflammatory types of macrophages, known under the generic term M2. In human breast carcinomas, tumor-associated macrophage (TAM) density correlates with poor prognosis. In mouse models of breast cancer, eliminating macrophages from the tumor site, either via genetic or therapeutic means, results in retarded tumor progression. Over the years, multiple signals from the mammary tumor microenvironment have been reported to influence the TAM phenotype and TAM have been propagated as anti-inflammatory M2-like cells. Recent developments point to the existence of at least two distinct TAM subpopulations in mammary tumors, based on a differential expression of markers such as CD206 or MHC II and different in vivo behaviour: perivascular, migratory TAM which are less M2-like, and sessile TAM found at tumor-stroma borders and/or hypoxic regions that resemble more M2-like or "trophic" macrophages. Hence, a further refinement of the molecular and functional heterogeneity of TAM is an avenue for further research, with a potential impact on the usefulness of these cells as therapeutic targets.
\end{abstract}

KEY WORDS: tumor-associated macrophage, mammary carcinoma, breast cancer, tumor microenvironment, M2

\section{Introduction}

For immunologists, macrophages are best known as central players in the innate immune system with an exceptional capacity to recognize, engulf and destroy pathogens. For developmental biologists however, macrophages are mainly seen as trophic cells that are instrumental for tissue remodelling during morphogenetic processes. Both functions represent different sides of the same coin, and illustrate the plasticity and polyvalency of this cell type. During postnatal mammary gland development, macrophages are recruited to the terminal end buds (TEBs) where they fulfil a nonredundant role in mammary ductal outgrowth. Indeed, TEB formation, their outgrowth in the mammary fat pad and duct branching are all impaired in mice lacking functional macrophages (GouonEvans et al., 2000). In recent years, it has become increasingly clear that the basic mechanisms behind breast tumor progression show similarities to the process of tissue reorganization in the developing mammary gland (Pollard 2009). As a matter of fact, all solid tumors can be considered as organ-like structures in which a

\footnotetext{
Abbreviations used in this paper: AP-1, activator protein-1; C/EBP, CCAAT/enhancer binding protein; DC-SIGN, dendritic cell-specific intercellular adhesion molecule3-grabbing non-integrin; EGF, epidermal growth factor; Gas6, growth arrest-specific 6; GM-CSF, granulocyte macrophage-colony stimulating factor; HIF-1, hypoxia inducible factor-1; HRG, histidine-rich glycoprotein; Hsp27, heat shock protein 27; IFN, interferon; IL, interleukin; IL-4R $\alpha$, IL-4 receptor $\alpha$; iNOS, inducible nitric oxide synthase; JNK, c-jun N-terminal kinase; M1, classically activated macrophage; M2, alternatively activated macrophage; M-CSF, macrophage-colony stimulating factor (= CSF-1, colony-stimulating factor 1); MDSC, myeloid-derived suppressor cell; MMR, macrophage mannose receptor; NF- $\mathrm{B}$, nuclear factor $\kappa \mathrm{B}$; PlGF, placental growth factor; S1P, sphingosine-1-phosphate; STAT3, signal transducer and activator of transcription 3; TADC, tumor-associated dendritic cell; TAM, tumor-associated macrophage; TEM, tie2-expressing monocyte; TGF, transforming growth factor; TMEM, tumor microenvironment of metastasis; TNF, tumor necrosis factor; TP, thymidine phosphorylase; VEGF, vascular endothelial growth factor.
} 
complex bidirectional interplay exists between transformed and nontransformed cells, the latter of which contain many macrophages. Originally strictly thought of as mediators of anti-tumor immunity, macrophages are now also known as potential contributors to tumor progression. As such, they can increase the survival and proliferative capacity of cancer cells, promote cancer cell motility, invasiveness and intravasation, drive angiogenesis, and mediate immunosuppression and extracellular matrix reorganization (Mantovani et al., 2002; Qian and Pollard 2010). This review mainly focuses on recent developments illustrating the heterogeneity of tumor-associated macrophages (TAM) at the primary tumor site, most studies of which were performed in mouse models of breast carcinoma formation and progression.

\section{Clinical relevance of tumor-associated macrophages in breast cancer}

Studying mechanisms of TAM-mediated tumor promotion in mouse models of breast carcinoma should be backed-up by clinical data illustrating the importance of this cell type in breast cancer patients. Several studies, mainly focussing on large groups of invasive ductal breast carcinomas, revealed a significant positive correlation between an increased level of macrophage infiltration and expression of typical monocyte/macrophage chemoattractants, such as CCL2 (also known as MCP-1), CCL5 (also known as RANTES) and CSF-1 (also known as M-CSF), in the tumor (Goede et al., 1999; Ueno et al., 2000; Lin et al., 2002). Both cancer cells and tumor-infiltrating cells are potential producers of these chemokines (Goede et al., 1999). A higher TAM density is typically associated with a high vascular density, suggesting an angiogenic activity of TAM in human tumors (Leek et al., 1996; Tsutsui et al., 2005). VEGF could be a potential mediator of TAM-driven angiogenesis as its expression is positively correlated with TAM levels (Tsutsui et al., 2005). Of importance, intensive macrophage infiltration is associated with known poor prognostic signs such as high tumor grade, low estrogen and progesterone receptor status and high tumor mitotic activity (Volodko et al., 1998). A similar link between the presence of a CSF-1 gene signature in the tumor, CCL2, CCL5 or VEGF levels, and other bad prognosticators reinforces the conception of TAM as contributors to breast tumor malignancy (Beck et al., 2009; Ueno et al., 2000). This is ultimately illustrated by a strong relationship between increased macrophage counts and reduced relapse-free and overall survival as an independent prognostic variable in invasive breast carcinoma patients (Leek et al., 1996). Corroborating these data, a recently developed stromaderived prognostic predictor-encompassing 163 stroma-expressed genes in human breast cancer - positions macrophage-associated genes in the poor outcome sample cluster (Finak et al., 2008). Overall, these studies provide statistically sound data linking the presence of TAM with bad prognosis in breast cancer patients, but provide little insight in the molecular mechanisms accounting for this phenomenon.

These significant, but still only correlative data in patients have now been supported by experimental evidence using mouse models. In M-CSF-deficient mice (Csf1op/Cs $\left.{ }^{f 1} o p\right)$, which lack mature macrophages, growth of transplantable tumors is markedly impaired (Nowicki et al., 1996). In addition, blocking M-CSF function via antisense oligonucleotides and siRNA, or inhibiting M-CSF receptor signaling, significantly suppresses tumor growth (Aharinejad et al.,
2004, Priceman et al., 2010). These studies were performed with transplantable tumors, and are hence relatively far from the human situation. However, transgenic mouse models such as MMTV-PyMT, expressing the polyoma middle $\mathrm{T}$ oncogene under control of the mouse mammary tumor virus promoter, spontaneously develop mammary tumors in stages comparable to the human situation. Mammary tumor progression in this MMTV-PyMT model is altered in a M-CSF null background, with no effect on tumor growth but a delay in the development to invasive, metastatic carcinomas (Lin et al., 2001). Of note, transgenic VEGF-A expression in the mammary gland restores tumor progression in M-CSF-deficient MMTV-PyMT mice, through stimulating tumor angiogenesis, leukocyte infiltration and cancer cell invasion (Lin et al., 2007). It should be noted however, that the levels of VEGF produced by TAM determine whether this protein has pro- or antitumoral activity. Indeed, TAM might produce very high VEGF levels leading to a very dense, but also dysfunctional vessel network. Deletion of VEGF specifically in TAM might cause vascular normalization and actually accelerate tumor progression (Stockmann et al., 2008). Irrespective of the mechanism, these data, obtained in genetically modified mice, clearly illustrate a non-redundant role for monocytes/macrophages in tumor progression. Finally, this conclusion is reinforced by experiments aimed at depleting TAM from mouse mammary tumors. DNA vaccination against legumain, a member of the asparaginyl endopeptidase family overexpressed by TAM, results in immune elimination of TAM and strongly reduced breast tumor growth and metastasis (Luo et al., 2006). Similarly, depletion of TAM in transgenic MMTV-HER-2 mice by an attenuated strain of Shigella flexneri, which induces apoptosis specifically in macrophages, resulted in a block of tumor growth and even tumor regression (Galmbacher et al., 2010).

\section{Macrophage activation states}

An important concept in the study of macrophages, including TAM, is the remarkable plasticity of these cells. Macrophages are implicated in functions as diverse as tissue development and homeostasis, wound-healing, inflammation and immunity. To accommodate for this, these cells are able to adopt diverse activation states depending on the stimuli they receive. Apopular classification system for macrophage activation, that has gained considerable success over the past years, is the M1/M2 dichotomy. Classically activated (or M1) macrophages are induced by Th1 cytokines, such as IFN- $\gamma$ and TNF- $\alpha$, and/or by recognition of pathogen-associated molecular patterns or endogenous danger signals. This type of macrophage is extensively studied and plays a pivotal role in propagating inflammation and pathogen clearance. More recently, it became clear that macrophage physiology is also significantly altered by the prototypical Th2 cytokines IL-4 and IL-13, inducing so-called bona fide alternatively activated macrophages or M2 (Martinez et al., 2009). Hence, the M1/M2 nomenclature reflects the status of macrophages functioning during ongoing polarized $\mathrm{T}$ helper (Th1 versus Th2) responses. In addition, a wide array of anti-inflammatory cues, such as IL-10, TGF- $\beta$, glucocorticoids, immune complexes and apoptotic cells, are known to influence the macrophage phenotype leading to different macrophage classification systems by different authors (Mantovani et al., 2004; Mosser et al., 2008; Martinez et al., 2009). A common denominator of all these non-M1 macrophages is their ability to dampen Th1 
cytokine-driven inflammation, to coordinate adaptive immune responses and to contribute to wound healing. On the other hand, IL-4/IL-13-induced M2 are implicated in Th2-driven pathologies, such as helminth infections and asthma (Martinez et al., 2009). Though the M1/M2 concept provides a useful working scheme, it should be realized that any form of classification underscores the complexity of the in vivo situation, where macrophages are exposed to a mixture of stimuli and will adopt mixed functional profiles. This is illustrated by the consensus gene signature for in vivo induced M2 in different pathologies, which not only contains genes that are strictly IL-4/IL-13-inducible such as E-cadherin (Van den Bossche et al., 2009), but equally so genes that are not inducible in vitro by any of the known M2 inducing stimuli (Hassanzadeh Ghassabeh et al., 2006).

Remarkably, in the human system, M-CSF and GM-CSF are used to differentiate more M2-like or M1-like macrophages from peripheral blood monocytes, respectively (Puig-Kröger et al., 2009). M-CSF-generated macrophages do not secrete the proinflammatory cytokines IL-12 and IL-23, but instead produce high levels of IL-10. Of note, this type of macrophage might resemble most the 'trophic', developmental type of macrophage (Pollard 2009). Considering the association of a M-CSF response signature with worse prognosis in breast carcinoma patients (Beck et al., 2009), trophic macrophages might also be present in the breast tumor microenvironment and function as important promotors of tumor progression. Exemplifying this, the surface markers folate receptor $\beta$ and DC-SIGN are found to be expressed on CD14 ${ }^{+}$CD68 ${ }^{+}$TAM from human breast adenocarcinomas, and are mainly regulated by cancer cell-derived M-CSF (Puig-Kröger et al., 2009; DominguezSoto et al., 2011). Cross-linking DC-SIGN on these TAM by cancer cells results in increased expression of IL-10, further amplifying the anti-inflammatory phenotype of the TAM (Dominguez-Soto et al., 2011). Interestingly, while M-CSF-stimulated macrophages might help cancer growth, GM-CSF treatment of mouse mammary tumors inhibits tumor growth and metastasis by invoking an antitumoral program in TAM (Eubank et al., 2009). Hence, a picture emerges whereby M2-like macrophages are protumoral, and M1-like cells exert antitumoral activity.

\section{Tumor-associated macrophage activation states in breast cancer}

The concept that TAM are mainly M2 activated, or even M2 'polarized', has been around for almost a decade (Mantovani et al., 2002), and is corroborated by the expression pattern of at least some of the TAM markers. For example, high production of IL-10 and low production of IL-12 is seen as a hallmark of all non-M1 macrophages, and is also applicable to most TAM populations in different cancer types. Also in breast cancer, high in vivo IL-10 production has been reported and is linked to reduced immune responsiveness (Guiducci et al., 2005; Weigert et al., 2009; PuigKröger et al., 2009). A skewing of the L-arginine metabolism towards higher arginase-1-mediated and lower iNOS-mediated L-arginine consumption is another typical feature of anti-inflammatory macrophages, at least in mice. High arginase enzyme activity has been reported in TAM from mouse breast cancer models (Movahedi et al., 2010). In addition, TAM from breast tumor-bearing mice showed a reduced tumoricidal capacity due to deficient expres-

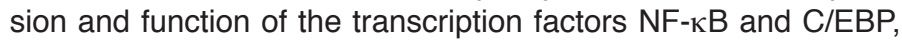

resulting in impaired iNOS gene expression and NO production (Torroella-Kouri et al., 2005). The predominant M2-like nature of breast tumor TAM has recently been supported by gene profiling data illustrating an immunoregulatory phenotype for these cells in different models (Ojalvo et al., 2009; Pucci et al., 2009; Movahedi et al., 2010). However, the picture of TAM being more M2-like is definitely not black and white, and TAM have been reported to express more M1-associated marker genes as well (Van Ginderachter et al., 2006a, Movahedi et al., 2010). This is probably linked to the existence of distinct TAM subpopulations with specialized functions, as will be discussed in the next chapter of this review, cautioning against overinterpretation of data based on total TAM populations.

Several microenvironmental stimuli were shown to influence the TAM phenotype in mammary tumors. In MMTV-PyMT tumors, IL-4 produced by tumor-infiltrating CD4+ Th2 cells skews the TAM into a metastasis-promoting population producing high levels of Epidermal Growth Factor (EGF). Consequently, the absence of $\mathrm{CD}^{+} \mathrm{T}$ cells or IL-4R $\alpha$ signalling in PyMT mice results in reduced pulmonary metastasis, without any effects on tumor latency, primary tumor growth and tumor angiogenesis (DeNardo et al., 2009). Also cathepsins, induced by IL-4 in the local tumor microenvironment, appear to contribute to the metastasis-promoting phenotype of PyMT TAM (Gocheva et al., 2010). The importance of a more M2like TAM polarization for tumor growth and metastasis is recently further highlighted by the effects of the serum protein histidine-rich glycoprotein (HRG). Under normal circumstances, HRG is rapidly degraded in the tumor microenvironment, but its forced expression switches M2 to M1 through downregulation of placental growth factor (PIGF). This event promotes antitumor immune responses and vessel normalization, thereby preventing metastasis and enhancing the effect of chemotherapy (Rolny et al., 2011).

Besides an interaction with tumor-infiltrating lymphocytes, TAM are expected to crosstalk with cancer cells. M-CSF is often produced by breast cancer cells and, as mentioned earlier, is able to regulate the expression of functionally important TAM markers such as folate receptor $\beta$, DC-SIGN and EGF (Goswami et al., 2005; Puig-Kröger etal., 2009; Dominguez-Soto et al., 2011). In accordance with a role for M-CSF, the Ets2 transcription factor, which is a direct effector of M-CSF signalling pathways, drives a transcriptional program in PyMT breast tumor TAM that promotes lung metastases formation (Zabuawala et al., 2010). Mechanistically, Ets2 represses a gene program that includes several inhibitors of angiogenesis, thus its ablation leads to decreased angiogenesis and decreased tumor growth. Besides M-CSF, human breast cancer cells secrete high amounts of Heat shock protein 27 (Hsp27), which accumulates to extremely elevated levels in the tumor interstitial fluid (Banerjee et al., 2011). Hsp27 causes the differentiation of monocytes to macrophages with an immune-tolerizing phenotype in vitro, and this type of macrophage is also found in human breast tumors. Hsp27-differentiated macrophages induce unresponsiveness in T cells and are strongly proangiogenic (Banerjee et al., 2011). In addition, dying cancer cells secrete sphingosine-1-phosphate (S1P) and TGF- $\beta$ that polarize macrophages towards an anti-inflammatory phenotype (Herr et al., 2009; Weigert et al., 2009). A knockdown of sphingosine kinase 2, the enzyme responsible for S1P production, in human MCF-7 breast cancer cells strongly impairs tumor xenograft growth associated with a deficiency in anti-inflammatory TAM generation (Weigert et al., 2009). Interestingly, S1P and TGF- $\beta$ induce HIF-1 activity, which has been shown to contribute 
to protumoral TAM functions (Herr et al., 2009). Indeed, myeloid cell-specific HIF-1 $\alpha$ deletion in the MMTV-PyMT background does not affect VEGF levels or vascularization, but reduces iNOS and arginase-1 expression in TAM, resulting in the loss of T-cell suppressive capacity (Doedens et al., 2010). Fra-1, a member of the AP-1 family of transcription factors, is also overexpressed in TAM from mouse breast tumors and appears to be important for the release of proangiogenic factors and the induction of $4 \mathrm{~T} 1$ migration and invasion (Luo et al., 2009). As a matter of fact, Fra-1 functions upstream of the well-known protumoral transcription factor STAT3 by stimulating IL-6 production, which in turn activates STAT3 (Luo et al., 2009). Hence, an entire transcriptional network governed by several transcription factors seems to be at work to skew macrophages at the tumor site into a protumoral phenotype. It should be realized however that the early skewing towards typical TAM functions, such as proangiogenic activity, already takes place at the earlier stages of myelomonocytic differentiation in the blood and bone marrow of tumor bearers, under the influence of cancer cell secreted factors such as VEGF, CXCL12 and PIGF (Hiratsuka et al., 2011; Laurent et al., 2011).

Finally, TAM from mouse breast tumors employ different mechanisms to alter the behaviour of cancer cells. Through the secretion of TNF- $\alpha$, TAM induce NF- $-\mathrm{B}$ and JNK activity in breast cancer cells resulting in enhanced invasiveness (Hagemann et al., 2005). The mitogen Gas 6 on the other hand increases cancer cell proliferation, and is strongly induced in tumor-conditioned macrophages (Loges et al., 2010). In addition, the interaction between invasive cancer cells and the extracellular matrix is facilitated by macrophage-derived SPARC, also known as osteonectin (Sangaletti et al., 2008). An overview of the mechanisms involved in the bidirectional interac- tion between breast tumor TAM and their environment, including cancer cells and T cells, is represented in Fig. 1.

\section{Heterogeneity of tumor-associated macrophages in established breast tumors}

Breast tumors are not only populated by tumor-associated macrophages, but also by other members of the mononuclear phagocyte system, including dendritric cells (TADC), Tie-2-expressing monocytes (TEM) and Myeloid-derived suppressor cells (MDSC). TEM elimination in vivo results in severely reduced tumor neovascularization, suggesting that these cells play a non-redundant proangiogenic role in tumors (De Palma et al., 2005). MDSC is a definition describing a function rather than a lineage of myeloid cells, and encompasses immature CD11b+Ly6C ${ }^{\text {hi }}$ Ly6G ${ }^{\text {neg }}$ monocytic (MO-MDSC) and CD11b+Ly6C intLy6G ${ }^{\text {hi }}$ granulocytic (PMN-MDSC) cells with a common immunosuppressive capacity, albeit through different mechanisms (Van Ginderachter et al., 2006b, Movahedi et al., 2008). Distinguishing these different myeloid cell types in tumors is not always trivial, as they are highly related, often express similar markers and are in some cases able to perform similar functions. Even within the TAM compartment, the existence of different TAM populations with different functions according to their presence in different regions of the tumor - areas of invasion, the stroma, perivascular areas, avascular and perinecrotic areas - has been predicted. In recent years, real-life images of different tumor microenvironments were produced and cancer cell/ stromal cell dynamics were visualized in real-time (Wyckoff et al., 2007, Egeblad et al., 2008, Kedrin et al., 2008). In mouse mammary tumors, macrophages are present in large numbers at the margins of the tumor and then decreasingly deeper in the tumors,

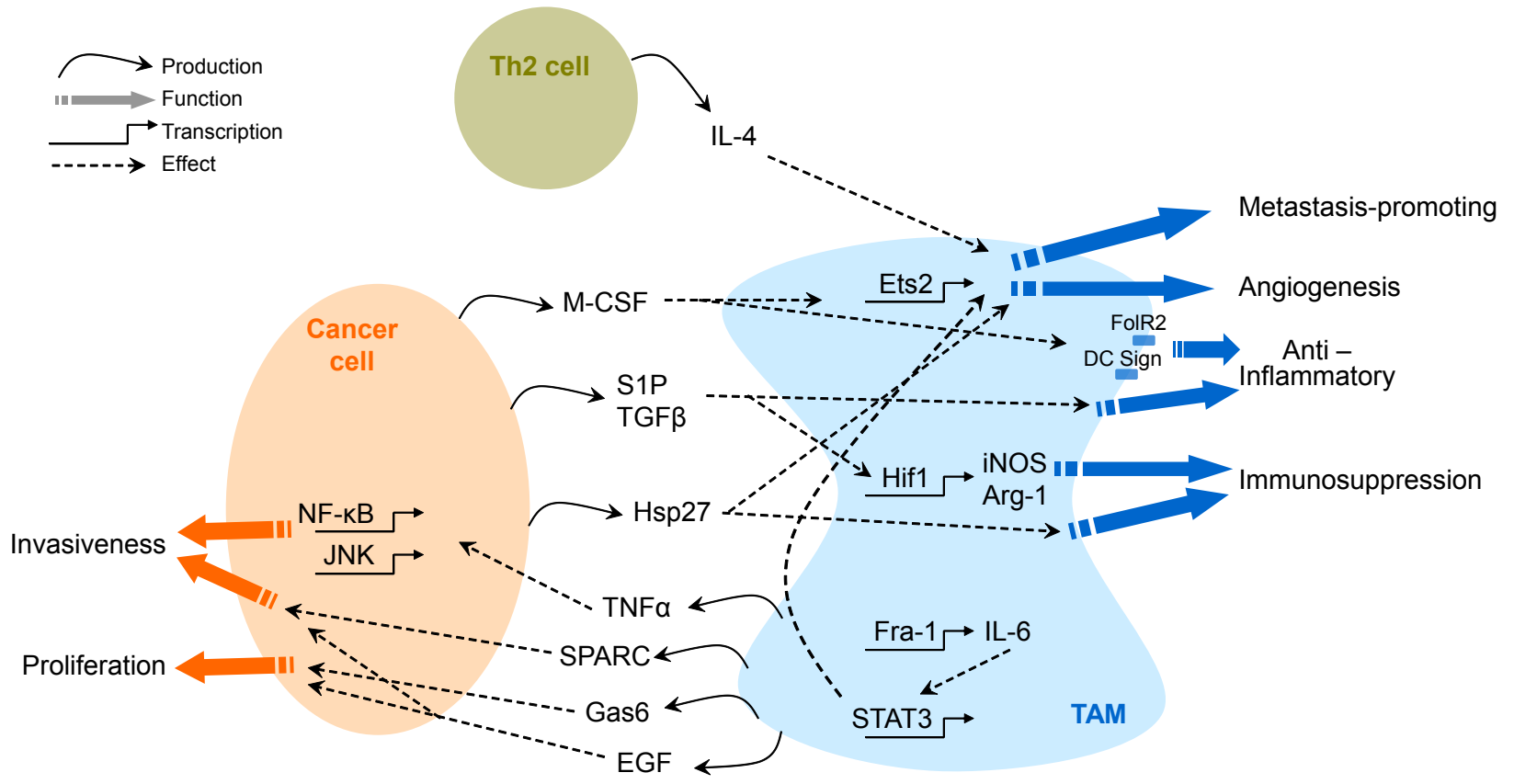

Fig. 1. Bidirectional interaction between tumor-associated macrophages from breast carcinomas and cells in their environment, including cancer cells and T cells. Distinct mediators secreted by breast cancer cells and tumor-infiltrating lymphocytes instruct a tumor-promoting phenotype on the resident macrophages, including metastasis-promoting, angiogenic, anti-inflammatory and immune suppressive functions. Several signalling pathways and transcription factors are implicated in this phenomenon. Vice versa, tumor associated macrophages (TAM) secrete a number of factors with a direct impact on cancer cell proliferation and invasiveness. 
Perivascular area

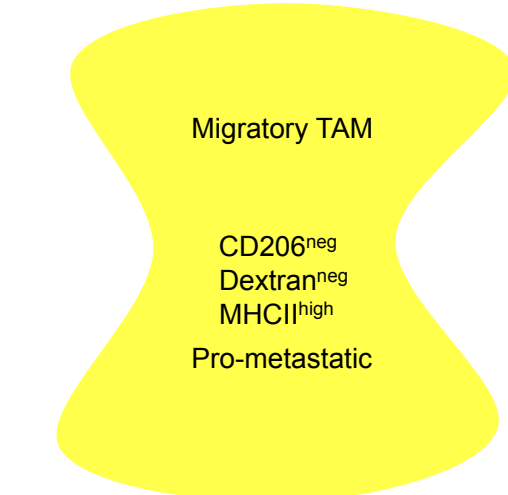

M1-like

Fig. 2. Tumor-associated macrophage (TAM) heterogeneity in breast carcinoma tumors. Scheme summarizing observations by several independent research groups, hinting to the existence of distinct TAM subsets, which are localized in different tumor compartments, exhibit a different molecular profile and exert specialized functions.
Tumor-stroma border/ Hypoxic area

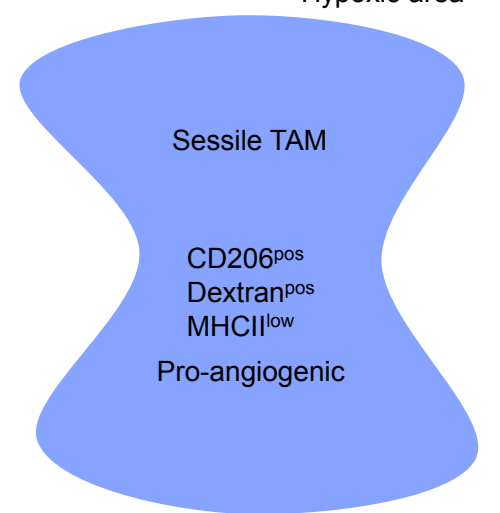

M2-like

as migratory CD68+MMR/CD206 ${ }^{\text {neg }}$ dextran ${ }^{\text {neg }}$ myeloid cells and sessile CD68+ ${ }^{+}$D206+ ${ }^{+}$dextran+ M2-type TAM, altogether clearly illustrating the existence of distinct macrophage types in breast tumors. In agreement with these data, a recent study employed CD206 and MHC II expression to discriminate between two TAM subpopulations in orthotopically grown mouse breast tumors (Movahedi et al., 2010). Interestingly, MHC II ${ }^{\text {high }}$ TAM are excluded from hypoxic avascular areas (hence more perivascular), are CD206 ${ }^{\text {neg }}$ and in general more $\mathrm{M} 1$-oriented, while hypoxic $\mathrm{MHC}$ Illow TAM express higher levels of CD206 and other M2associated markers. At the functional level, the MHC Illow $^{\text {CD206 }}{ }^{+}$hypoxic TAM were more proangiogenic. Though clinical data on TAM heterogeneity in human breast tumors are almost non-existing, one study hints to this possibility. In breast carcinoma patients, expression of thymidine phosphorylase (TP) in TAM provided an independent prognostic value, with macrophage $\mathrm{TP}^{+}$tumors having a significantly worse prognosis (Toi et al., 1999). Even patients having an extensive accumulation of $\mathrm{CD}^{2} 8^{+} \mathrm{TAM}$ could be categorized in two

where many were found in association with blood vessels either as single cells or in clusters (Wyckoff et al., 2007). The presence of TAM near blood vessels is of great importance for the course of the disease, as these TAM attract cancer cells and move with them in a directed fashion, resulting in the extravasation of cancer cells only in the neighbourhood of such macrophages. As a matter of fact, the density of such tripartite interactions between invasive cancer cells, macrophages and endothelial cells (also called the tumor microenvironment of metastasis or TMEM) is able to predict the presence of distant metastases in breast cancer patients (Robinson et al., 2009). Mechanistically, the coordinated movement of cancer cells and perivascular macrophages can be explained by a paracrine positive feedback loop, whereby M-CSF produced by cancer cells and EGF produced by perivascularTAM are instrumental for cell migration and invasion (Wyckoff et al., 2007, Goswami et al., 2005). Triggering of this loop can occur under the influence of growth factors such as heregulin- $\beta 1$ and CXCL12 (Hernandez et al., 2009). Movement of cancer cells in the neighbourhood of blood vessels has also been observed in a study using cancer cells that express the photoswitchable protein Dendra2 (Kedrin et al., 2008). Regions in different tumor microenvironments of the same orthotopically grown tumor were photoswitched and cancer cell motility was followed using intravital microscopy through a mammary imaging window. While there was little migration in avascular regions, photoswitched cells were more mobile in a vascular microenvironment containing perivascular macrophages. In the latter regions, cancer cells infiltrated larger areas and lined up along blood vessels, illustrating the existence of at least two distinct microenvironments within the same tumor. Along the same line, Egeblad etal., (2008) showed migratory behaviour of M-CSFR+ myeloid cells at the tumor-stroma borders, but not within the tumor mass, using spinning disk confocal microscopy on mouse mammary tumors. These authors also identified other markers with the ability to discriminate between migratory and sessile cells. Non-migratory cells present within the tumor mass were mostly $\mathrm{CD}^{+}{ }^{+} \mathrm{CD}^{206^{\text {neg }}}$ and did not ingest intravenously injected dextran $\left(\right.$ dextran $\left.^{\text {neg }}\right)$. Cells at the tumor-stroma border could be distinguished subgroups with strikingly different diagnoses: a good prognostic macrophage TPneg group and a poor prognostic macrophage TP ${ }^{\text {pos }}$ group. These data suggest the existence of both antitumor and protumor TAM types in human breast carcinomas, whereby their balance possibly influences outcome of the disease.

The existence of TAM subpopulations has obvious consequences for the interpretation of existing gene expression data sets of these cells. For example, a high-density gene expression analysis of TAM from PyMT tumors was performed on the $\mathrm{M}-\mathrm{CSFR}+\mathrm{F} 4 / 80^{+} \mathrm{Gr}-1^{\text {neg }}$ dextran $^{+}$TAM population, but not on $\mathrm{M}$ CSFR ${ }^{+} \mathrm{F} 4 / 80^{+} \mathrm{Gr}-1^{\text {neg }}$ dextran ${ }^{\text {neg }}$ tumor-associated cells, though these cells are most likely also TAM (Ojalvo et al., 2009). Hence, the conclusion that PyMT TAM express higher levels of genes related to immune suppression, development and angiogenesis is only true for the TAM subpopulation studied. The fact that conclusions for one TAM population can not be extrapolated to another one is exemplified by follow-up work from the same lab, comparing the dextran+ TAM to the TAM population comigrating with cancer cells in an in vivo migration assay (Ojalvo et al., 2010). The latter are probably similar to the perivascular TAM in the imaging study by Wyckoff et al., (2007), and the CD68+ CD206 ${ }^{\text {neg }}$ dextran ${ }^{\text {neg }}$ TAM in the imaging study by Egeblad et al., (2008). Surprisingly enough, these TAM populations were very different at the gene expression level. Of interest, the dextran+ TAM expressed elevated levels of nearly all genes belonging to a consensus gene signature for in vivo-induced M2-like macrophages, including CD206 (Hassanzadeh Ghassabeh et al., 2006). In that respect, these cells resemble the MHC Il low CD206+ M2-like TAM subpopulations from orthotopically grown mammary tumors, while the $\mathrm{MHC}$ II $^{\text {high }} \mathrm{CD} 206^{\text {neg }} \mathrm{M} 1$-like TAM from these tumors might be similar to the migratory/perivascular TAM (Movahedi et al., 2010). Overall, the existence of following two TAM subpopulations seems consistent throughout several independent studies by different researchers: (i) M-CSFR+Gr$1^{\text {neg }}$ Dextran ${ }^{\text {neg }} C D 206^{\text {neg }} \mathrm{MHC}$ II $^{\text {high }}$ perivascular TAM that can be co-opted by cancer cells to migrate and are generally less M2oriented; and (ii) sessile M-CSFR ${ }^{+} \mathrm{Gr}-1^{\text {neg }}$ Dextran ${ }^{+} \mathrm{CD} 206{ }^{+} \mathrm{MHC} \mathrm{II}^{\text {low }}$ TAM found at tumor-stroma borders and/or hypoxic regions that 
resemble more M2-like or "trophic" macrophages (Fig. 2).

\section{Concluding remarks}

For many years, the development of cancer therapeutics was mainly a search for ways to interfere with cancer cell-intrinsic characteristics. However, evidence in breast carcinoma patients and experimental mouse mammary tumor models make a strong case for the implication of TAM in regulating tumor progression and metastasis. Hence, significant efforts have been made to better characterize this "other half of the tumor", and data are available to proclaim TAM as potential targets for therapeutic intervention.

In order to develop novel strategies for TAM-directed anticancer therapies, several ongoing research lines will be important. These include the determination of TAM molecular signatures, using omics approaches, which might yield novel targets for intervention. In addition, the better characterization of distinct TAM subsets, residing in different tumor regions and performing specialized functions, promises to gain better insights in fundamental TAM/ cancer cell crosstalk and might provide the opportunity to specifically target the most protumoral TAM. Finally, it might well be that diverse tumor-associated host cells (such as myofibroblasts) will fall into a diversity of functional subtypes like it was found for TAM.

\section{References}

AHARINEJAD S, PAULUS P, SIOUD M., HOFMANN M, ZINS K, SCHÄFER R, STANLEY ER, ABRAHAM D (2004). Colony-stimulating factor-1 blockade by antisense oligonucleotides and small interfering RNAs suppresses growth of human mammary tumor xenografts in mice. Cancer Res 64: 5378-5384.

BANERJEE S, LIN C-F L, SKINNER KA, SCHIFFHAUER LM, PEACOCK J, HICKS DG, REDMOND EM, MORROW D, HUSTON A, SHAYNE M et al. (2011). Heat shock protein 27 differentiates tolerogenic macrophages that may support human breast cancer progression. Cancer Res 71: 318-327.

BECKAH, ESPINOSAI, EDRIS B, LIR, MONTGOMERYK, ZHU S, VARMAS, MARINELLI RJ, VAN DE RIJN M, WESTRB (2009). The macrophage colony-stimulating factor 1 response signature in breast carcinoma. Clin Cancer Res 15: 778-787.

DENARDO DG, BARRETO JB, ANDREU P, VASQUEZ L, TAWFIK D, KOLHATKAR $\mathrm{N}$, COUSSENS LM (2009). CD4+ T cells regulate pulmonary metastasis of mammary carcinomas by enhancing protumor properties of macrophages. Cancer Cell 16: 91-102.

DE PALMA M, VENNERI MA, GALLI R, SERGI SERGI L, POLITI LS, SAMPAOLESI M, NALDINI L (2005). Tie2 identifies a hematopoietic lineage of proangiogenic monocytes required for tumor vessel formation and a mesenchymal population of pericyte progenitors. Cancer Cell 8: 211-226.

DOEDENS AL, STOCKMANN C, RUBINSTEIN MP, LIAO D, ZHANG N, DENARDO DG, COUSSENS LM, KARIN M, GOLDRATH AW, JOHNSON RS (2010). Macrophage expression of hypoxia-inducible factor- $1 \alpha$ suppresses T-cell function and promotes tmor progression. Cancer Res 70: 7465-7475.

DOMINGUEZ-SOTOA, SIERRA-FILARDIE, PUIG-KRÖGERA, PEREZ-MACEDAB, GOMEZ-AGUADO F, CORCUERAMT, SANCHEZ-MATEOS P, CORBIAL (2011). Dendritic cell-specific ICAM-3-grabbing nonintegrin expression on M2-polarized and tumor-associated macrophages is macrophage-CSF dependent and enhanced by tumor-derived IL-6 and IL-10. J Immunol 186: 2192-2200.

EGEBLAD M, EWALD AJ, ASKAUTRUD HA, TRUITT ML, WELM BE, BAINBRIDGE E, PEETERS G, KRUMMEL MF, WERB Z (2008). Visualizing stromal cell dynamics in different tmor microenvironments by spinning disk confocal microscopy. Dis Mod Mech 1: 155-167.

EUBANK TD, ROBERTS RD, KHAN M, CURRY JM, NUOVO GJ, KUPPUSAMY P, MARSH CB (2009). Granulocyte macrophage colony-stimulating factor inhibits breast cancer growth and metastasis by invoking an anti-angiogenic program in tumor-educated macrophages. Cancer Res 69: 2133-2140.

FINAK G, BERTOS N, PEPIN F, SADEKOVA S, SOULEIMANOVA M, ZHAO H, CHEN H, OMEROGLU G, METERISSIAN S, OMEROGLU A, HALLETT M, PARK
M (2008). Stromal gene expression predicts clinical outcome in breast cancer. Nat Med 14: 518-527.

GALMBACHERK, HEISIG M, HOTZC, WISCHHUSEN J, GALMICHEA, BERGMANN B, GENTSCHEV I, GOEBEL W, RAPP UR, FENSTERLE J (2010). Shigella mediated depletion of macrophages in a murine breast cancer model is associated with tumor regression. Plos One 5: e9572.

GOCHEVA V, WANG H-W, GADEA BB, SHREE T, HUNTER KE, GARFALL AL, BERMAN T, JOYCE JA (2010). IL-4 induces cathepsin protease activity in tmorassociated macrophages to promote cancer growth and invasion. Genes Dev 24: $241-255$.

GOEDE V, BROGELLI L, ZICHE M, AUGUSTIN HG (1999). Induction of inflammatory angiogenesis by monocyte chemoattractant protein-1. Int J Cancer 82: 765-770.

GOSWAMI S, SAHAIE, WYCKOFF JB, CAMMER M, COXD, PIXLEY FJ, STANLEY ER, SEGALL JE, CONDEELIS JS (2005). Macrophages promote the invasion of breast carcinoma cells via a colony-stimulating factor-1/epidermal growth factor paracrine loop. Cancer Res 65: 5278-5283.

GOUON-EVANS V, ROTHENBERG ME, POLLARD JW (2000). Postnatal mammary gland development requires macrophages and eosinophils. Development 127: 2269-2282.

GUIDUCCI C, VICARI AP, SANGALETTI S, TRINCHIERI G, COLOMBO MP (2005). Redirecting in vivo elicited tumor infiltrating macrophages and dendritic cells towards tumor rejection. Cancer Res 65: 3437-3446.

HAGEMANN T, WILSON J, KULBE H, LI NF, LEINSTER DA, CHARLES K, KLEMM F, PUKROP T, BINDER C, BALKWILL FR (2005). Macrophages induce invasiveness of epithelial cancer cells via NF-KB and JNK. J Immunol 175: 1197-1205.

HASSANZADEH GHASSABEH G, DE BAETSELIER P, BRYS L, NOËL W, VAN GINDERACHTER JA, MEERSCHAUT S, BESCHIN A, RAES G (2006). Identification of a common gene signature for type II cytokine-associated myeloid cells elicited in vivo during different pathologies. Blood 108: 575-583.

HERNANDEZ L, SMIRNOVA T, KEDRIN D, WYCKOFF J, ZHU L, STANLEY ER, COX D, MULLER WJ, POLLARD JW, VAN ROOIJEN N, SEGALL JE (2009). The EGF/CSF-1 paracrine invasion loop can be triggered by heregulin beta 1 and CXCL12. Cancer Res 69: 3221-3227.

HERR B, ZHOU J, WERNO C, MENRAD H, NAMGALADZE D, WEIGERT A, DEHNE N, BRÜNE B (2009). The supernatant of apoptotic cells causes transcriptional activation of HIF-1(alpha) in macrophages via sphingosine-1-phosphate and transforming growth factor-(beta). Blood 114: 2140-2148.

HIRATSUKA S, DUDA DG, HANG Y, GOEL S, SUGIYAMA T, NAGASAWA T, FUKUMURA D, JAIN RK (2011). C-X-C receptor type 4 promotes metastasis by activating p38 mitogen-activated protein kinase in myeloid differentiation antigen (Gr-1)-positive cells. Proc Natl Acad Sci USA 108: 302-307.

KEDRIN D, GLIGORIJEVIC B, WYCKOFF J, VERKHUSHA VV, CONDEELIS J, SEGALL JE, VAN RHEENEN J (2008). Intravital imaging of metastatic behavior through a mammary imaging window. Nat Meth 5: 1019-1021.

LAURENT J, HULL EF, TOUVREY C, KUONEN F, LAN Q, LORUSSO G, DOUCEY MA, CARLIONI L, IMAIZUMI N, ALGHISI GC, FAGIANI E, ZAMAN K, STUPP R, SHIBUYA M, DELALOYE JF, CHRISTOFORI G, RUEGG C (2011). Proangiogenic factor PIGF programs CD11b+ myelomonocytes in breast cancer during differentiation from their hematopoietic progenitors. Cancer Res 71: 3781-3791.

LEEK RD, LEWIS CE, WHITEHOUSE R, GREENALL M, CLARKE J, HARRIS AL (1996). Association of macrophage infiltration with angiogenesis and prognosis in invasive breast carcinoma. Cancer Res 56: 4625-4629.

LINEY, NGUYENAV, RUSSELLRG, POLLARD JW (2001). Colony-stimulating factor 1 promotes progression of mammary tumors to malignancy. JExp Med 193: 727-739.

LIN EY, GOUON-EVANS V, NGUYEN AV, POLLARD JW (2002). The macrophage growth factor CSF-1 in mammary gland development and tumor progression. $J$ Mammary Gland Biol Neoplasia 7: 147-162.

LIN EY, LI J-F, BRICARD G, WANG W, DENG Y, SELLERS R, PORCELLI SA, POLLARD JW (2007). VEGF restores delayed tumor progression in tumors depleted of macrophages. Mol Oncol 1: 288-302.

LOGES S, SCHMIDT T, TJWA M, VAN GEYTE K, LIEVENS D, LUTGENS E, VANHOUTTE D, BORGELD, PLAISANCE S, HOYLAERTS M et al. (2010). Malignant cells fuel tumor growth by educating infiltrating leukocytes to produce the mitogen Gas6. Blood 115: 2264-2273.

LUO Y, ZHOU H, KRUEGER J, KAPLAN C, LEE S-H, DOLMAN C, MARKOWITZ D, WU W, LIU C, REISFELD RA, XIANG R (2006). Targeting tumor-associated mac- 
rophages as a novel strategy against breast cancer. J Clin Invest 116: 2132-2141.

LUO YP, ZHOU H, KRUEGER J, KAPLAN C, LIAO D, MARKOWITZ D, LIU C, CHEN T, CHUANG T-H, XIANG R, REISFELD RA (2009). The role of proto-oncogene Fra-1 in remodeling the tumor microenvironment in support of breast tumor cell invasion and progression. Oncogene 29: 662-673.

MANTOVANI A, SOZZANI S, LOCATI M, ALLAVENA P, SICAA (2002). Macrophage polarization: tumor-associated macrophages as a paradigm for polarized M2 mononuclear phagocytes. Trends Immunol 23: 549-555.

MANTOVANI A, SICA A, SOZZANI S, ALLAVENA P, VECCHI A, LOCATI M (2004). The chemokine system in diverse forms of macrophage activation and polarization. Trends Immunol 25: 677-686.

MARTINEZ FO, HELMING L, GORDON S (2009). Alternative activation of macrophages: an immunologic functional perspective. Annu Rev Immunol 27: 451-483.

MOSSER DM, EDWARDS JP (2008). Exploring the full spectrum of macrophage activation. Nat Rev Immunol 8: 958-969.

MOVAHEDI K, GUILLIAMS M, VAN DEN BOSSCHE J, VAN DEN BERGH R, GYSEMANS C, BESCHIN A, DE BAETSELIER P, VAN GINDERACHTER JA (2008). Identification of discrete tumor-induced myeloid-derived suppressor cell subpopulations with distinct T-cell suppressive activity. Blood 111: 4233-4244.

MOVAHEDI K, LAOUI D, GYSEMANS C, BAETEN M, STANGE G, VAN DEN BOSSCHE J, MACK M, PIPELEERS D, IN‘T VELD P, DE BAETSELIER P, VAN GINDERACHTER JA (2010). Different tumor microenvironments contain functionally distinct subsets of macrophages derived from Ly6C(high) monocytes. Cancer Res 70: 5728-5739.

NOWICKI A, SZENAJCH J, OSTROWSKA G, WOJTOWICZ A, WOJTOWICZ K, KRUSZEWSKIAA, MARUSZYNSKIM, AUKERMANSL, WIKTOR-JEDRZEJCZAK W (1996). Impaired tumor growth in colony-stimulating factor 1 (CSF-1)-deficient, macrophage-deficient op/op mouse: evidence for a role of CSF-1-dependent macrophages in formation of tumor stroma. Int $J$ Cancer 65: 112-119.

OJALVO LS, KING W, COX D, POLLARD JW (2009). High-density gene expression analysis of tumor-associated macrophages from mouse mammary tumors. Am $J$ Pathol 174: 1048-1064.

OJALVO LS, WHITTAKER CA, CONDEELIS JS, POLLARD JW (2010). Gene expression analysis of macrophages that facilitate tumor invasion supports a role for Wnt-signaling in mediating their activity in primary mammary tumors. $J$ Immunol 184: 702-712.

POLLARD JW (2009). Trophic macrophages in development and disease. Nat Rev Immunol 9: 259-270.

PRICEMAN SJ, SUNG JL, SHAPOSHNIK Z, BURTON JB, TORRES-COLLADO AX, MOUGHON DL, JOHNSON M, LUSIS AJ, COHEN DA, IRUELA-ARISPE ML, WU L (2010). Targeting distinct tumor-infiltrating myeloid cells by inhibiting CSF-1 receptor: combating tumor evasion of anti-angiogenic therapy. Blood 115: $1461-1471$.

PUCCI F, VENNERI MA, BIZIATO D, NONIS A, MOI D, SICA A, DI SERIO C, NALDINI L, DE PALMA M (2009). A distinguishing gene signature shared by tumor-infiltrating Tie2-expressing monocytes, blood "resident" monocytes, and embryonic macrophages suggests common functions and developmental relationships. Blood 114: 901-914.

PUIG-KRÖGER A, SIERRA-FILARDI E, DOMINGUEZ-SOTO A, SAMANIEGO R, CORCUERAMT, GOMEZ-AGUADOF, RATNAMM, SANCHEZ-MATEOSP, CORBI $A L$ (2009). Folate receptor $\beta$ is expressed by tumor-associated macrophages and constitutes a marker for M2 anti-inflammatory/regulatory macrophages. Cancer Res 69: 9395-9403.

QIAN B-Z, POLLARD JW (2010). Macrophage diversity enhances tumor progression and metastasis. Cell 141: 39-51.
ROBINSON BD, SICA GL, LIU YF, ROHAN TE, GERTIER FB, CONDEELIS JS, JONES JG (2009). Tumor microenvironment of metastasis in human breast carcinoma: a potential prognostic marker linked to hematogenous dissemination. Clin Cancer Res 15: 2433-2441.

ROLNY C, MAZZONE M, TUGUES S, LAOUI D, JOHANSSON I, COULON C, SQUADRITO ML, SEGURA I, LI X, KNEVELS E et al. (2011). HRG inhibits tumor growth and metastasis by inducing macropage polarization and vessel normalization through downregulation of PIGF. Cancer Cell 19: 1-14.

SANGALETTI S, DI CARLO E, GARIBOLDI S, MIOTTI S, CAPPETTI B, PARENZA M, RUMIO C, BREKKEN RA, CHIODONI C, COLOMBO MP (2008). Macrophagederived SPARC bridges tumor cell-extracellular matrix interactions toward metastasis. Cancer Res 68: 9050-9059.

STOCKMANN C, DOEDENS A, WEIDEMANN A, ZHANG N, TAKEDA N, GREENBERG JI, CHERESH DA, JOHNSON RS (2008). Deletion of vascular endothelial growth factor in myeloid cells accelerates tumorigenesis. Nature 456: 814-818.

TOI M, UENOT, MATSUMOTOH, SAJI H, FUNATAN, KOIKE M, TOMINAGAT (1999). Significance of thymidine phosphorylase as a marker of protumor monocytes in breast cancer. Clin Cancer Res 5: 1131-1137.

TORROELLA-KOURI M, MA X, PERRY G, IVANOVA M, CEJAS PJ, OWEN JL, IRAGAVARAPU-CHARYULU V, LOPEZ DM (2005). Diminished expression of transcription factors nuclear factor $\mathrm{\kappa B}$ and CCAAT/Enhancer binding protein underlies a novel tumor evasion mechanism affecting macrophages of mammary tumor-bearing mice. Cancer Res 65: 10578-10584.

TSUTSUI S, YASUDA K, SUZUKI K, TAHARA K, HIGASHI H, ERA S (2005). Macrophage infiltration and its prognostic implications in breast cancer: the relationship with VEGF expression and microvessel density. Oncol Rep 14: 425-431.

UENO T, TOI M, SAJI H, MUTA M, BANDO H, KUROI K, KOIKE M, INADERA H MATSUSHIMA K (2000). Significance of macrophage chemoattractant protein-1 in macrophage recruitment, angiogenesis, and survival in human breast cancer. Clin Cancer Res 6: 3282-3289.

VANDEN BOSSCHE J, BOGAERTP, VAN HENGELJ, GUERIN CJ, BERX G, MOVAHEDI K, VAN DEN BERGH R, PEREIRA-FERNANDES A, GEUNS JM, PIRCHER $\mathrm{H}$ et al. (2009). Alternatively activated macrophages engage in homotypic and heterotypic interactions through IL-4 and polyamine-induced E-cadherin/catenin complexes. Blood 114: 4664-4674.

VAN GINDERACHTER JA, MOVAHEDIK, HASSANZADEH GHASSABEH G, MEERSCHAUT S, BESCHIN A, RAES G, DE BAETSELIER P (2006a). Classical and alternative activation of mononuclear phagocytes: picking the best of both worlds for tumor promotion. Immunobiol 211: 487-501.

VAN GINDERACHTER JA, MEERSCHAUT S, LIUY, BRYS L, DE GROEVE K, HASSANZADEH GHASSABEH G, RAES G, DE BAETSELIERP (2006b). Peroxisome proliferator-activated receptor $\gamma$ (PPAR $\gamma$ ) ligands reverse CTL suppression by alternatively activated (M2) macrophages in cancer. Blood 108: 525-535.

VOLODKO N, REINER A, RUDAS M, JAKESZ R (1998). Tumor-associated macrophages in breast cancer and their prognostic correlations. Breast 7: 99-105.

WEIGERTA, SCHIFFMANN S, SEKARD, LEY S, MENRAD H, WERNO C, GROSCH S, GEISSLINGER G, BRÜNE B (2009). Sphingosine kinase 2 deficient tumor xenografts show impaired growth and fail to polarize macrophages towards an anti-inflammatory phenotype. Int J Cancer 125: 2114-2121.

WYCKOFF JB, WANG Y, LIN EY, LI J-F, GOSWAMI S, STANLEY ER, SEGALL JE, POLLARD JW, CONDEELIS J (2007). Direct visualization of macrophage-assisted tumor cell intravasation in mammary tumors. Cancer Res 67: 2649-2656.

ZABUAWALA T, TAFFANY DA, SHARMA SM, MERCHANT A, ADAIR B, SRINIVASAN R, ROSOL TJ, FERNANDEZ S, HUANG K, LEONE G, OSTROWSKI MC (2010). An Ets2-driven transcriptional program in tumor-associated macrophages promotes tumor metastasis. Cancer Res 70: 1323-1333. 


\section{Further Related Reading, published previously in the Int. J. Dev. Biol.}

The interplay between macrophages and angiogenesis in development, tissue injury and regeneration Silvia Nucera, Daniela Biziato and Michele De Palma Int. J. Dev. Biol. in press (doi: 10.1387/ijdb.103227sn)

\section{Cancer stem cells and angiogenesis}

Yue Zhao, Qi Bao, Andrea Renner, Peter Camaj, Martin Eichhorn, Ivan Ischenko, Martin Angele, Axel Kleespies, Karl-Walter Jauch and Christiane Bruns

Int. J. Dev. Biol. in press (doi: 10.1387/ijdb.103225yz)

Reprogramming of melanoma cells by embryonic microenvironments

Alejandro Díez-Torre, Ricardo Andrade, Cristina Eguizábal, Elixabete López, Jon Arluzea, Margarita Silió and Juan Aréchaga Int. J. Dev. Biol. (2009) 53: 1563-1568

Cadherin-mediated cell-cell adhesion and tissue segregation in relation to malignancy Ramsey A. Foty and Malcolm S. Steinberg

Int. J. Dev. Biol. (2004) 48: 397-409

Analysis of tenascin mRNA expression in the murine mammary gland from embryogenesis to carcinogenesis: an in situ hybridization study

I Kalembey, T Yoshida, K Iriyama and T Sakakura

Int. J. Dev. Biol. (1997) 41: 569-573

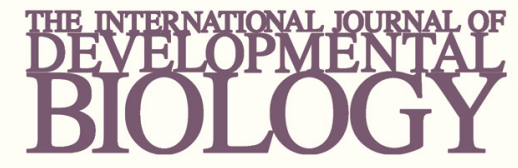

Volume 54 Nos. 6/7
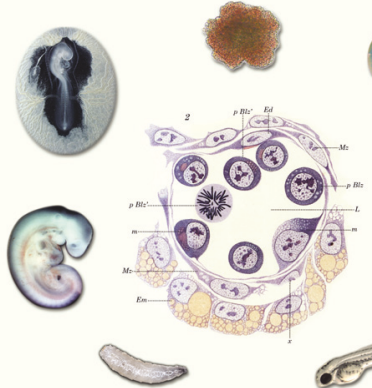

Developmental Hematopoiesi
5 yr ISI Impact Factor $(2010)=2.961$

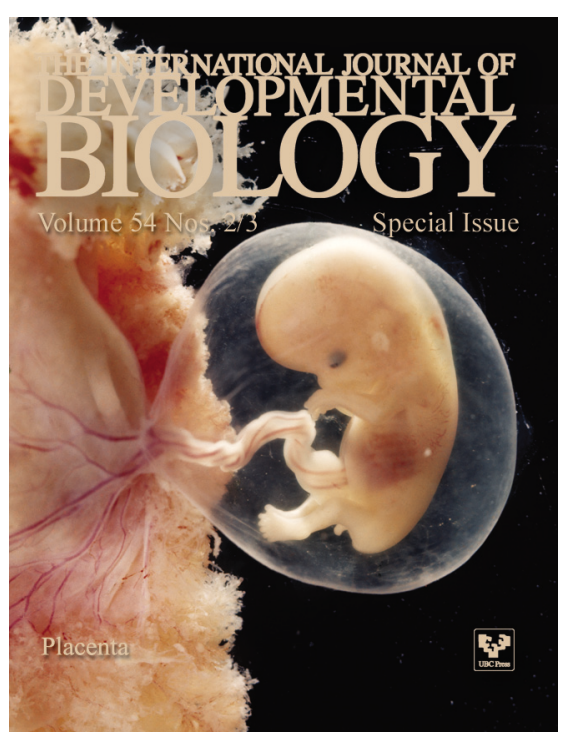

